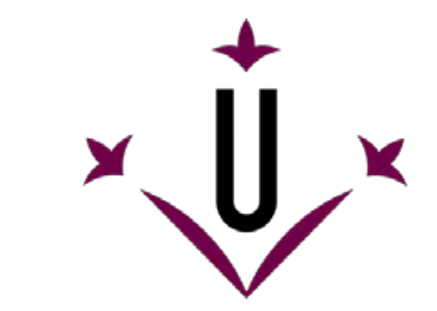

Universitat de Lleida

Document downloaded from:

http://hdl.handle.net/10459.1/67845

The final publication is available at:

https://doi.org/10.1177/0269758019897145

Copyright

(c) Villacampa Estiarte, Carolina, 2019 


\title{
Forced marriage as a lived experience: victims' voices
}

\author{
Carolina Villacampa \\ University of Lleida. Department of Public Law \\ Jaume II, 73. 25001 Lleida (Spain). cvillacampa@dpub.udl.cat
}

\begin{abstract}
The official response to forced marriage in the majority of European countries has been to criminalise the practice. Based on racial stereotypes and outdated Orientalist perspectives, this overlooks the prior need for appropriate empirical analysis in order to better understand the reality of the practice being regulated, and fails to provide victims with the means of protection they need beyond the framework of criminal law. Devising a suitable and effective strategy to address this form of victimisation instead requires an in-depth understanding of the effects that victims of these practices endure, and what the victims themselves would consider best practice in terms of assistance and protection. In view of these primary objectives, after the existence of forced marriages in Spain had been demonstrated by the corresponding quantitative research, a qualitative research study followed, conducted through interviews with victims of forced marriage, the results of which are presented here. This was also done with the secondary aim to draw up the basic guidelines for an intersectional programme of action to address this process of victimisation.
\end{abstract}

Key words: forced marriage, victims' experiences, effects of victimisation, victim support received, victim support intended.

\section{Introduction}

Forced marriage is generally understood as a marriage that is held without the consent of one or both parties (FRA, 2014). The most traditional definitions only recognise cases in which coercion or duress is used to force one or both of them to marry, thus differentiating the practice from arranged marriage (Anitha and Gill, 2011a; Home Office, 2000; HM Government, 2010; Igareda, 2017). However, it has increasingly become the norm to understand such cases within a framework of gender-based violence (Bunting et al., 2016; Gill and Anitha, 2011a) and through an intersectional lens, according to which processes of power and subordination in the postmodern society are not only explained by the binary system of sex and gender, but by a multiplicity of factors, such as race, class and gender (Crenshaw, 1989, 1991; Nixon and Humphreys, 2010; Sokoloff and Dupont, 2005). Applying this approach to the phenomenon under analysis here, it results in the adoption of a concept of forced marriage less attached to the binary conceptualisation of coercion and consent (Anitha and Gill, 2011a) and, as a consequence, in a more comprehensive definition of it, making more fluid the limits between this category and the arranged marriage. According to this more contemporary conceptualisation of forced marriage, also sustained here, it is accepted that methods of force might not necessarily involve violence or the threat of violence, but could also be carried out by means of coercive control (Anitha and Gill, 2009, 2011a). Moreover, as well as being forced to enter into a marriage against their will, victims may continue to endure coercion throughout its term, which could also prevent any potential termination (Gangoli et al., 2011). What is more, if forced marriage is understood as a process, a pattern of behaviour more than an event, among other possible consequences derived from the assumption of a broader concept of this phenomenon, it can also encompass cases in which women have not yet been forced into marriage but are at risk of being so (Chantler and McCarry, 2019), as it is shown in this paper. 
Various international bodies and non-governmental organisations (NGOs) have condemned the practice of forced marriage on a global scale, particularly those in which one or both of the parties are underage (UNICEF 2001, 2008, 2014). Eurocentric perspectives based on Orientalist ideas, on the patronizing western representation of eastern societies as static and undeveloped (Naber, 2010; Said, 1979), and racial stereotypes have often led to an improper association of the practice with cultural minorities. In recent years, however, studies conducted in western countries have refuted such ideas to reveal that forced marriage is a reality which also occurs in western societies as a form of gender-based violence (Anitha and Gill, 2011b; Chantler et al., 2009; Patton, 2018; Razack, 2004). In effect, a UNICEF report issued in 2014 indicated that, although uncommon, forced marriage was indeed practised in western countries as well (UNICEF, 2014). In the United States, although this question has only very recently received legal attention (Love et al., 2018; Martin, 2018), one extensive research study was conducted by the Tahirih Justice Center in 2011 in which a total of 500 assistance organisations revealed that there had been as many as 3,000 cases in the country in the preceding two years (Tahirih Justice Center, 2011). In Europe, the Forced Marriage Unit (FMU) was created in 2005 as a victim support unit in the United Kingdom and has published annual quantitative data on forced marriage in the country since 2012, claiming to have made between 1,200 and 1,400 annual interventions since then. In 2017, the number of cases assisted was 1,196, with a high proportion involving victims under the age of $18(29.7 \%)$, as well as women and girls $(77.8 \%)$, and the countries of origin were also diverse (Home Office-Foreign \& Commonwealth Office, 2018). Germany has also conducted a national assessment on forced marriage (Mirbach et al., 2011) which revealed that, in 2008, as many as 3,443 women and girls sought advice from entities and organisations. Of these, $70 \%$ were under 21 , and $30 \%$ were under 18 years of age. In Italy, a research study conducted in 2009 by the organisation Associazione Trama di Terre detected 33 cases in in the Emilia-Romagna region (Trama di terre, 2014), all except three involving women and girls. A study conducted by Hamel in 2011 demonstrated the existence of the practice in France, and showed that the proportion of nonconsensual marriages was higher among immigrant women aged between 51 and 60 than among those aged between 26 and 30, which led them to conclude that the practice was in clear decline in France (Hamel, 2011). In Spain, data on the subject has been very limited until very recently. Most has been sourced from police records in Catalonia, although qualitative data was also obtained more recently from the MATRIFOR project, which identified risk factors among specific women forced into marriage (Igareda et al, 2016). In 2017, the first quantitative mapping study on the incidence of forced marriage in Spain was carried out through an online survey issued to a real sample of 150 victim service providers. 62 of these providers identified victims of forced marriage and completed data sets for 57 victims. These results showed that all victims were women and $77 \%$ were under 21 years of age (of whom $33 \%$ were under the age of 18). The highest proportion of victims originated from the Maghreb (42\%) and subSaharan Africa (25\%), while 21\% were Spanish, mainly of Muslim religion (69\%) (Villacampa and Torres, 2019).

The legal approach to forced marriage taken by the majority of European countries, based on the aforementioned patronizing ideas from the West about the East, has been to criminalise it as a specific offence and to settle cases exclusively through the use of criminal justice (Ebeturk and Cowart, 2017; FRA, 2014; Gill and Anitha, 2011b; Sabbe et al. 2014), especially after the approval of the Council of Europe Convention on preventing and combating violence against women and domestic violence in 2011 (Istanbul Convention). Other measures have included raising the legal minimum age for marriage (Gangoli and Chantler, 2009; Hester et al., 2008) and preventing the family reunification of under the age of 18 spouses (Wijffelman, 2017). The effectiveness of such measures in eliminating the practice of forced marriage or adequately addressing the victims' needs of protection remains far from established. A 
significant number of European countries ${ }^{1}$ have taken the approach of criminalising forced marriage as a specific offence. In 2015, for example, Spain criminalised cases where violence or serious intimidation is used to force one or both parties into marriage. This has drawn criticism from scholars, not only in terms of the privilege accorded to such crimes over others that might also be considered cases of forced marriage, but also due to the general ineffectiveness of criminal law as the primary measure. Such an approach fails to acknowledge the difficulties of intervention in such private family affairs, and provides no other supportive measures (Maqueda, 2016; Torres, 2015; Villacampa, 2018). Moreover, in Spain, as in the majority of cases, such legislation was adopted with no prior empirical analysis conducted to determine the effects such practices have on victims, and how best to legally address these.

Forced marriage is a complex reality, related not only to individual freedoms but also to gender-based and family violence, as well as to certain harmful traditional practices (Gangoli and Chantler, 2009; Gangoli et al., 2011; Gill and Anitha, 2011a). In order to be able to devise suitable strategies of detection, assistance and victim protection, it is important to tackle the scale of the issue with the use of both quantitative and qualitative data and the perspectives of the victims themselves. We decided to conduct qualitative research on victims' experiences in view of these points. Having demonstrated through the above-mentioned quantitative research study that forced marriage is indeed conducted in Spain as well (Villacampa and Torres, 2019), it was decided that qualitative analysis on the experiences of those who have endured the practice would be an appropriate method of determining the impact on victims and the protection they need. The use of a qualitative methodology would allow for a more comprehensive study (Corbin and Strauss, 2008; Denzin and Lincoln, 2002; Marshall and Rossman, 2006; May, 2005), specifically analysing how victims cope with the experience, what official support they have received, and what they considered to be most suitable in terms of protection. In order to overcome the limits of policies that criminalise forced marriage, based on Orientalist perspectives that focus only on the cultural aspects of the practice and tend to alienate non-western cultures, such questions must be understood. This is also crucial in moving towards victim-centred strategies that address the practice as a form of gender-based violence requiring an intersectional approach (Anitha and Gill, 2009; Ebeturk and Cowart, 2017; Sabbe et al., 2014; Villacampa, 2018), not only because it has been shown how forced marriages can entail other forms of abuse (Swegman, 2016), but mostly because this type of victimisation is explained by different subordination intersecting factors, beyond the gender, that need to be addressed in order to deal appropriately with victims.

\section{Research methodology}

Having completed the quantitative research study, for this next stage of research we opted for a system of purposive sampling that led to the selection of a group of victims with whom we would carry out a series of semi-structured, in-depth interviews. The sample finally selected was a group of five victims, all of whom were women, since no male victims had been identified in the quantitative study, which reflects the majority of studies on the practice (Mirbach et al., 2011; Psalia et al., 2016; Tahirih Justice Center, 2011). The characteristics of the 5 victims are set out in Table 1.

(table 1 around here)

\footnotetext{
${ }^{1}$ In chronological order, the following countries have criminalised forced marriage in their respective justice systems: Norway (2005), Austria (2006), Belgium (2007), Denmark (2008), Cyprus (2009), France and Germany (2011), Greece, Slovakia, Switzerland and the UK (2014), Luxembourg and Malta (2014), Bulgaria, Italy, Spain, Portugal, Sweden, Croatia and Slovenia (2015) and the Netherlands (2016).
} 
Table 1. Characteristics relating to victims interviewed

\begin{tabular}{lllll}
$\begin{array}{l}\text { Interview } \\
\text { number }\end{array}$ & $\begin{array}{l}\text { Place of birth of } \\
\text { interviewee }\end{array}$ & Age of interviewee & $\begin{array}{l}\text { Did the marriage } \\
\text { take place? } \\
\text { (YES/NO) }\end{array}$ & $\begin{array}{l}\text { Age of the interviewee } \\
\text { when the marriage } \\
\text { took place }\end{array}$ \\
\hline V 1 & Spain & 28 & YES & 16 \\
\hline V 2 & Spain & 29 & YES & 15 \\
\hline V 3 & Senegal & 27 & YES & 18 \\
\hline V 4 & Spain & 29 & NO & - \\
\hline V 5 & Gambia & 27 & NO & -
\end{tabular}

Access to the interviewees was facilitated by the assistance NGOs that had taken part in the previous quantitative study, completing the online survey and thus demonstrating that they had supported victims of forced marriages. After victims were initially approached by the organisation and consented to take part in the research, they were then approached by the research team, who outlined the content of the interview and again requested their consent to be interviewed.

This research study initially aimed to analyse a larger number of victim testimonies; however, given the huge difficulty of finding survivors of the practice who would consent to being interviewed, we were able to access a small number only. In spite of this, the testimonies presented in the interviews were considered to be sufficiently expressive of the experiences endured by victims, the effects on them, and what they might therefore hope for in terms of official protection. Ethical approval of this research was not received from any institution, since this was not required to grant the project by the Spanish Ministry funding it and the ethics committee from the university in which the research was conducted, while currently reporting on ethical aspects of any proposed research, only reported on ethical issues related to biomedical research at that time. However, ethical aspects of the research were taken into consideration, especially those related to the consent of victims to intervene in this study, both when designing and executing the research project.

The methodology used for data collection consisted of semi-structured, in-depth interviews that were carried out face to face and lasted between 30 and 90 minutes. Interviews were conducted in Spanish or Catalan depending on the preference expressed by the interviewees, provided that all of them were fluent at least in one of these languages. The interview model used was made up of a first set of questions about the personal experience the victim had endured. Depending on how and when facts emerged, interviewees were asked about the place the marriage was held or was intended to be held, their response to the marriage, the impact on them and the consequences of the process, and their personal situation at the time of interview. A second set of questions focused on the help the interviewee had received in order to resolve the situation. They were asked to provide details on what had led them to seek help, the precise support they were looking for, the organisations they approached, the kind of resources they were offered, and how they would evaluate the assistance they received and the level of knowledge of the professionals involved. Finally, a third set of questions aimed at determining the interviewees' views on best practice for victim protection, that is, what support measures they believed should be implemented, and what the role of criminal justice should be in resolving such conflicts.

The interview model was used as a guideline, rather than a set of rules that would dictate the tone of the interview and conversation. Participation in the study was voluntary and express consent was given. The interviews took place throughout July 2018 in various cities in Catalonia, and were recorded and later completely transcribed. 
The data were analysed using a thematic analysis methodology (Guest et al., 2012), following the stages that comprise this: familiarisation with the data, generating initial codes for the data, developing and reviewing the themes, and then defining and naming these themes (Braun and Clarke, 2006).

\section{Results of qualitative research from victim interviews}

\subsection{Victims' experiences: personal circumstances and methods of victimisation}

As table 1 shows, three of the five women interviewed were married to their intended spouses, while the remaining two had faced the threat of a marriage that did not, in the end, take place. Of these two women, one had been in a situation of imminent risk: the interviewee herself knew that she was engaged to be married to an identified family member. The risk the other interviewee faced was less clear, suggesting that the prospective spouse was undecided. Plans had been made, however, to send her back to her country of origin, allegedly to spend her school holidays, but unlike her two younger brothers, who were to fly on different days and with a return ticket, she had a one-way ticket.

The five interviewees revealed that it was at a very early age that they were informed by their closest family members that they would have to marry a spouse they had not chosen, some having barely reached puberty at this point, although marriages took place at a later point in time. This reflects the findings of the quantitative study (Villacampa and Torres, 2019) and previous research (Gangoli and Chandler, 2009; Kazimirski et al., 2009; Mirbach et al., 2011).

"Because the person I was supposed to marry had been arranged since I was very young" (V 1)

"Yes, they tried to marry me off. The first time I experienced this was when I was 13. They told me that I was old enough now, I was very developed, I had breasts and it was about time that I got married. I first experienced this when I was 13, with a cousin.” (V 2)

"In my case, it was when I was 14 when they had me engaged to a cousin who lived in the USA. As in, someone I only knew from talking to him a few times on the phone, but had never seen in person. We hadn't agreed anything. You see, I was a child." (V 4)

Usually, the engagement partner arranged was relatively close to the victim, within their family circle. The interviewees often referred to this prospective or future spouse as a "cousin" in their family. They were usually considerably older than the victim: at the time of the arrangement, while the victims were in their adolescence, the prospective spouses were adults of over 30 years of age. In one case, the victim discovered that she would become the youngest spouse of a man who already had several.

“(...) and it turned out that that person had three wives and I was going to be the fourth. He had children, and they were older than I was... And when they introduced us, he turned out to be a relative of mine: we weren't even second cousins, but cousins, cousins, because the man's mother and my own mother had the same father, as in, we were blood relatives, blood relatives... We were about 25 years apart in age. In other words, it felt like being in a relationship with my own father..." (V 1)

Those who informed the victims that they would be married or were engaged invariably belonged to their close family circle. In general, the father plays the main role. According to the women's testimonies, fathers seem to have the final say in concluding arrangements and deciding when to tell their daughters, with the exception of one case in which the interviewee suggested that it was her uncles who had made the arrangement, as shown in the following quotation:

"Yes - well, my uncles. Because when marriages are arranged and it's not your parents who are in charge, it's got to be an uncle. My parents are in charge of their nephews and nieces, and their parents are in charge of me." (V 2) 
The mothers were confined to a more passive role in the process, although they were generally aware of the situation, as the transcripts below demonstrate. Regardless, the interviews conducted suggest that the victims have a more sympathetic view of the roles their mothers played in the process than that of their fathers, seeing them instead as potential liberators or people who might be able to understand what their daughters are experiencing.

\begin{abstract}
"Eventually, it came to a final conclusion. My uncles all got together - there were 3 of them - and some other older people, I don't remember who anymore, and they told me that I had to get married. And I said I didn't want to. My mother was there for the whole thing, right? And she didn't say anything, she didn't express any opinion." (V 2)

"It was my father's family who made the proposal, in fact. My father is very particular, he's very reserved, that's what he's like about religion... I don't think my mother would ever have considered it if my father hadn't kind of gone for it by himself to make sure the whole thing happened. So it was my father's family who tied it all up in the end, I don't think my mother's family had much to do with it. The man is the one with the most say in the matter and it's him who has the final say about who his daughter marries." (V 4)
\end{abstract}

In terms of the means used to coerce the victims into marriage, the qualitative data reflect the findings of the quantitative study. Violence, intimidation and deception, methods typically associated with the crime of forced marriage, were uncommon, at least in the initial stages of the process. The use of each of these methods was found respectively in $8 \%, 18 \%$ and $11 \%$ of cases (Villacampa and Torres, 2019). For one interviewee, violence had been used from the very beginning: her family had abused her since she was a child. Except for this case, family pressure was the main method used to coerce the victims into marriage, as previous studies have also shown (Gill and Harvey, 2017; Hemmings and Khalifa, 2013).

"I had no choice... Anyway, I didn't accept it, because I had been engaged once before, but they broke it off because I didn't want to get married at that point either. So it was like... I'm a bad daughter, I'm the stubborn one, I say no to every man they suggest... I said that I didn't want to, but they told me that anyway I couldn't stay at home then, with all my friends getting married and me here not wanting to get married..." (V 3)

"Yes. In the end they gave me an ultimatum: I had a month to find a husband who I wanted to marry, otherwise I would have to marry my cousin. And if I didn't marry my cousin, they would take me to Africa and then..." (V 2)

In the case of the interviewee who had endured abusive treatment from her family since childhood, the violence began before the marriage came about, as her testimony suggests.

"I'm telling you, in my mind I never wanted to, it was just to please my family. Once I got there I was in my family's town and then they took me to a town in the middle of nowhere... it's a bit complicated, but... as a kind of punishment for all those years that I abandoned my family and for what I put them through, they kept me in one of those small towns that hardly exist anymore where there are no buses, where there's nothing at all... they kept me there for a week, tied up, abused, anyone who came by could beat me... basically, they could do anything they wanted to me." (V 1)

As shown, however, this was not the case reported by the majority of interviewees. Rather, the process was usually a lived experience in which victims were led by circumstances; by forces beyond their control, which they could not openly resist; and by a context in which they were not expected to make decisions, as others would make these for them. Only rarely did violence occur. As the following transcripts suggest, this was such that one of the interviewees was not even aware of the exact moment when the marriage ceremony, said to have taken place during a family party, was held. Another interviewee did not know until a while afterwards that the marriage, held in her parents' country of origin, was fortunately legally invalid in Spain.

"The party ended. I didn't speak to my mother, nobody came to explain anything to me, they just told me that I had a husband. And after about a week, I went to ask my aunt why people were telling me I had a husband. And she told me that I was married now. And I told her that nobody had said anything to me. And she said: 'how could nobody have said anything to you? You were at the party as well!' And that's how I knew I was married." (V 2) 
"My father went off, took my NIE [identity document for foreign residents in Spain], and had me married off there... When he came back, he came back with just a marriage certificate and he said, 'Oh, XXX, you have an appointment in court, because you need to get the man here...' Thank God, I booked an appointment at the court, I signed the papers, but thank God, I don't know what happened, but it turned out that the marriage certificate wasn't valid." (V 1)

However, the fact that violence was not generally used before the marriage took place does not mean that it did not occur after the engagement was secured, as will be discussed among the consequences of the practice.

Finally, regarding the location in which the marriage took place or was intended to, this is more difficult to determine in the case of the two interviewees who, in the end, were not married. Regarding those who were, only one of the victims born in Spain was married within Spanish territory, which reflects the low incidence of marriages held in Spain $(30 \%)$ demonstrated in the quantitative study (Villacampa and Torres, 2019). The other interviewee was taken to her parents' country of origin, where she was married, before relocating to Spain in the company of her spouse.

\subsection{Consequences of the experience for victims of forced marriage}

As shown, the use of violence as a means to coerce the victim was not the general trend in the cases analysed here. However, in the three cases in which the marriage took place, the situation invariably became increasingly violent. An in-depth analysis reveals that these are unquestionably cases turning into forced marriage, even having departed from a traditional and narrow understanding of the term not assumed here. As for the different forms of violence and abuse experienced by victims, it will be shown how the findings of this investigation are consistent with those of previous studies showing that forced marriages usually intersect with other forms of physical, psychological and sexual abuse (Swegman, 2016).

In one of the cases, as shown, violent conduct had already been a reality for a long time. The violence used by the victim's family before the marriage continued after it had taken place, since the victim remained living with her mother in Spain, separately from her spouse, who was still based in Senegal. She had been abused by her mother since childhood and this did not relent after her marriage. She was also sexually abused by her spouse every time she was taken to Senegal to visit him, over the course of the 10 years during which these circumstances took place. In this case, therefore, the victim endured both parental and marital violence.

"I didn't have any children, I made sure to avoid that. I was married to him from the age of 16 to 25 and every year they made me go to Senegal to have sex with him, to make a kind of life with him. I would get injections so I couldn't get pregnant, but always in secret, as obviously if my family found out... but even with these precautions, I'm telling you, it was rape... Every year I went and stayed there for a month, sometimes a month and a half, and I came back. Basically, it was a month and a half of hell every year." (V 1)

In the other two cases where the marriage took place, while the victim may have originally been coerced into the marriage by family pressure, it was the spouse who began to behave violently once they were living together, generally as a way of controlling the victim. This was not necessarily condoned by the woman's family, and was indeed sometimes against their will.

\footnotetext{
"Yes, I had to come and live here with him [when she turned 18; she had continued living with her parents after she was married at the age of 15]. I put a bolt on the bedroom door because I didn't want anything to do with him. In the end, he was really strong and always ended up breaking down the door. And when I arrived here I made good friends with one of the neighbours, who was an old lady, and she helped me a lot, because I told her to call the police if she heard me scream or if she heard a lot of noise in the house. I escaped from the house many times because this person didn't let me go out, and I went through my neighbour's house... but when I came back home there would be more beatings, more rows..." (V 2)

"I left because I always had problems with him, he beat me... Yes, we've had quite a lot of problems. And in the end, he told me he couldn't do it anymore and I said that I couldn't either, and so he brought me here to see if I would reconsider, if I would behave myself and be with him (...) And since he brought me here,
} 
other people also came to ask me to go back to him. And I didn't want to because of everything he'd done to me, he had abused me, he had beaten me and everything, and above all because I didn't love him and he told me that he would never be separated from me." (V 3)

In none of the cases where the marriage took place did the victim begin to feel any love or affection for the person whom they had married and lived with at intervals. On the contrary, living together exacerbated the difficulties in the relationship. The absence of any kind of positive feeling towards their spouse or future spouse is notable in the way that none of the interviewees refer to them by first name: many refer to them simply as a "cousin", otherwise using pejorative names such as "that man" or even "the cockroach".

In the cases analysed, the relationships broke down and the spouses consequently ceased to cohabit. Invariably, the victims experienced this as a real liberation.

"When I finished taking all my things away from the apartment (taking advantage of one day when my husband was away on a trip) the 'cockroach' was going up in the lift as I was running down the stairs, but without looking back. There was one moment, like in a movie, when he was going up in the lift and I was going down and we crossed paths, and I said to myself: 'this is my path to freedom'. And I ran away without looking back, I jumped on the motorbike of my current husband, and then I looked behind for a second and thought "it's over!"” (V 2)

However, marital separation also entailed another, much more painful experience for the victims in such cases. They were also separated, at least for a certain period of time, from their family of origin. This also occurred in the two cases where marriages did not take place, later analysed in greater depth.

\subsection{Victims' responses and emotional reactions}

When they were told that they were engaged or that they had to marry, most of the interviewees, at least those who were based in Spain at the time, initially resisted the arrangement and made it clear that they had no intention of marrying the person selected. In cases where the interviewee was older and felt more socially influential when the engagement or the marriage itself took place, they directly refused to accept the circumstances.

\footnotetext{
"I said I didn't want to, that I didn't want anything to do with him, and the day I found a partner I would run away, I would leave. And of course he got angry and hit me. He said to me, 'You're very young, you'll change your mind and love me in the end.' And I replied that I never would, I was very sure about that." (V 2)

"Well, from the moment they first brought it up, obviously I completely rejected the marriage. A while later, I started going out with a boy who lived nearby and that made the situation a whole lot worse, because I was already engaged, even though it was against my will... I said to them, 'Look, you might as well deal with it, because for me it's as if the marriage doesn't exist, I've never consented and I don't love him, so you're going to have to break it off when you see that it's not going anywhere."' (V 4)

“[To her father:] I'm only 16 years old, I haven't even finished school, I have to look for a job and make a living here. I'm very grateful that you've brought me here, so don't take me back there [to Africa] now." (V 5)
}

However, when the victim was younger or their perspective was held in lower esteem socially, their methods of resistance tended to be less overt. They desperately looked for help or expressed a more passive kind of resistance, without openly questioning the decisions of those in charge.

\footnotetext{
"Desperate, I went to my neighbour, who I always say is my 'white grandma', she's always looked after me since I was small: she would come to collect me from school, I would stay with her, she would help me with homework... that kind of thing, basically she's my white grandma. I told her what was happening and she went to talk to my parents, which was how I managed to delay it for 2 years, until I was 15." (V 2)
} 
"When I got engaged to that guy [a previous fiancé], in the end they broke it off because I wouldn't stop crying, I made myself ill by not eating for almost 3 days... yes, I made myself ill but they still wanted to tie me up and take me to get married in that state..." (V 3)

Initially, at least, the circumstances did not change and the victims' families remained determined to have their daughters married. The interviewees highlighted how women experiencing such circumstances feel, at the very least, fury, defencelessness and frustration at the disregard for their power to make important decisions about their own lives.

"It's like an attack on your freedom, on your sense of self, on you as an individual, and on your power to make decisions. You feel like your opinion is worth nothing, you're like a puppet and you have to do what others want. It's kind of this feeling of fury and of not having the power to say anything, damn, they don't even tell you what's going on! It's frustrating, because you try to say no, that this isn't normal, that they can't force you into it, but they think it's all fine: 'How is it not normal? This is what we did, what our parents did, our whole culture, there's nothing wrong with it!'” (V 4)

In the case of those who had been to school in Spain, victims also experienced feelings of misunderstanding: they could not understand how their mothers, who had been through similar circumstances, let the same thing happen to their daughters. These interviewees felt resentment towards their family for not allowing them to follow the Western model of life where falling in love, finding a partner and getting married were all intrinsically linked. Their mothers - who, paradoxically, tend to be quite passive participants in the marriage arrangements - were the ones they held most responsible for the helpless situation in which they found themselves. This perhaps because, as previous research has shown, mothers might be playing a relevant role in the process of grooming their daughters into unwanted marriages (Chantler and McCarry, 2019), although not having an active role in the marriage arrangements themselves, what may cause their daughters to react against the ambivalent position their mothers have in the whole process: as protective female figures, on the one hand, but also as agents of the course leading them to marry forcibly, on the other.

"I was most angry with my mother, as I said to her: 'Mama, you are a woman like me, how could you let them do this to me?", (V 2)

"It was something that my father would do. But my mother... in fact, at one point, I said to her: 'how can you let them do this to me?", (V 4)

Despite blaming their closest relatives, they still felt strong emotional bonds with their families and a sense of obligation to fulfil their parents' expectations, not to disappoint them, to obey them and submit to the marriage for the sake of family harmony, as other studies have revealed (Gill and Harvey, 2017). Some even began to convince themselves that they had been wrong and that, no matter how difficult, they had to put up with the marriage arranged for them.

“That's just how it is and I've got to do it and I've got to accept it. Eventually, I just accepted it... or I basically accepted it... I didn't think I had any way out of that life.” (V 1)

"And they took his side! He punctured the tyres of my car so I couldn't go out to study, he beat me, but I was the one in the wrong! Eventually, I ended up believing that I had been the one in the wrong the whole time. If the whole world was against me, I thought I must have been somehow in the wrong." (V 2)

The interviewees were trapped between a belief that marriage should be for love and accepting the one their family had arranged for them. This dilemma could become personally devastating, especially in cases where violence was continuously used, as shown in the following words of one of the interviewees.

"I felt as if I had been raped again, I felt... as if I were worthless, as if I were just a rag that people could use and throw away whenever they wanted. I don't know... I felt insulted, despised, as if I were nothing... I'm telling you, there was a point in my life between the ages of 16 and 25 when I felt like - excuse me - a complete shit, something people could do what they wanted with, and well that's basically what happened, they did what they wanted with me..." (V 1) 
As most of the interviewees have demonstrated in relatively explicit terms, they found themselves in a situation where they felt like they were living two parallel realities, like "living between two worlds", as one interviewee put it: the world they had been taught about at school or among their peers, and the one forced upon them at home. This tension invariably ended, if only temporarily, in separation from their families. Some remain separated, while others have since been reconciled. Therefore, in addition to the negative emotions and responses caused, victims also endured the pain of losing their closest family, at least on a temporary basis.

\begin{abstract}
"For me things were quite bad, because I lost people who I had really loved all my life, people who had treated me well too, who I didn't want to lose. But, anyway, it's too late now, because that's what happened, that's what happened... You know, when it's been some time since a relationship broke down, because of resentment, when it's painful, if you've been cut off for a long time, it's very difficult to make things right." (V 3)
\end{abstract}

\title{
3.4 The role of the family and community
}

As demonstrated under the previous sub-headings, the role that the victim's family plays in the arrangement and celebration of such marriages is unquestionable. In the three cases of contracted marriage we were able to analyse, the victims even remained in abusive marriages precisely because of family pressure, to avoid being a disappointment to their parents.

In effect, particular worldviews, ways of life and attitudes towards gender roles and women are passed on from generation to generation through the nuclear family unit, although also through extended family. These norms are also dictated by the wider community of origin. In the media, rather than in academic research, a clear link has been established between the practice of forced marriage and certain religions or belonging to certain communities (Anitha and Gill, 2011b; Chantler et al, 2009; Gangoli et al., 2011; Kazirmirski et al., 2009; Razack, 2004). However, while the results of the previous quantitative study showed that a majority of victims (69\%) were of Muslim religion (Villacampa and Torres, 2019), from the results of the qualitative research it is difficult to determine if this practice is more clearly linked with certain cultures, rather than with the practice of certain religions.

“It's not about religion, it's about culture, I think. I don't think it's just about religion, it's a mix between religion and culture, because there are people who don't force you, who are Muslims but don't force you to get married." (V 3)

That said, the interviewees' families also attempted to remain faithful to their roots while based in Europe, to such an extent that two of the interviewees, one born in Spain, made it clear without being prompted that they had suffered genital mutilation. In accordance with such roots and traditions, which the families seek to preserve after the process of migration, the burden rests largely on women to observe a certain code of conduct and thus uphold family honour. It is also women who are held responsible for making sure that younger women in the family remain faithful to this as well, in such a way that women might be acting not only as biological, but also as cultural reproducers (Chantler and McCarry, 2019). This demonstrates the link between forced marriage and honour-based violence, as an indirect form of gender-based violence, as established in previous studies (Begikhani et al., 2015; Gill, 2014; Gill and Brah, 2014; Yurdakul and Korteweg, 2013).

"My mother didn't take it very well because women are always under a lot of pressure with their daughters' upbringing; as in, if I do something wrong, they'll blame her for not having brought me up well, or in other words they'll think things are going wrong because she hasn't brought me up well, because she should have been stricter. So, mothers bear the brunt of what happens with their daughters, and there's nothing really they can do to escape that." (V 4) 
According to the interviewees, this code of conduct requires women to be submissive, obedient and peaceful, to be good wives who stay at home, know how to cook, and, ultimately, accept the marriage that has been arranged for them. Breaking this code places the family in a state of dishonour, in a position of weakness faced with what others might say or think. It is therefore the family that pressures their daughters, possibly channelling the will of the wider community, not only coercing them to remain in a situation of marital discontent, but also, as this study has revealed, even making them victims of intimate partner violence. Indeed, according to the interviews, the families often appealed to the importance of their daughters' behaviour in maintaining honour or dishonour in order to put pressure on them, with the precise aim of reestablishing this kind of honour.

"I didn't want to back down in the face of family pressure, because I was always about to finally go for it and then my family would come and start drilling into me and talking and talking... and I would end up giving in. Giving in because I thought about my father and mother who kept saying: "What will people say? I don't want a daughter who is divorced!"; so I would be disappointing my parents..." (V 2)

This is because, as most of the interviewees have suggested, these families live under the watchful eye of other members of their community and what they might say or think. Moreover, as one of the interviewees suggested in telling us that her mother wished to get on well with her father's other wives in Africa, parental success is valued strictly according to their daughters getting married and living a life in line with the code of family honour.

In these circumstances, it is unsurprising that it is the family themselves who pressure their daughters most overtly when faced with the prospect of a marital separation, as the woman begins to try and start a new life. At this point, the family pressure that aims to get everything back to 'normal' can become even more intense. In cases where parental violence had been used before the forced marriage was arranged, the pressure reached the point of blackmail, while most cases saw the methods of coercion become stronger to some degree.

"And what happened [after the separation]?: I got calls from this person, and from my family, telling me to go back to him. How dare I leave home and leave my husband alone! Open the door and let him in!" (V 2)

It has also been observed that when family pressure does not prove sufficient in reestablishing what is traditionally considered to be a normal situation, when the family is unable to force their daughter into submission, there is often a reaction from the wider community. The woman in question is shunned; the community rejects all contact with her.

\footnotetext{
"When all of this happened, the husbands of black friends I had told them not to associate with me because I was a divorcee. They started to avoid me. They stopped calling me and coming to see me (...). Yes, it's crazy, because I'm generally very resilient, I'm a fighter and all that, but the community was destroying me." (V 2)

"When people saw me in the street they would say: 'Your father's in hospital because of you.' Friends who turned their backs on me because I had reported him. But I hadn't reported him, I had only told the judge that I didn't want to go [to Gambia]." (V 5)
}

Despite these pressures, some of the interviewees suggested that they understood that their families had behaved in what they understood to be their daughter's best interest. According to what they had been taught, this was what they had to do to bring them up properly.

\footnotetext{
"They always try to pressure you, to manipulate you. They do it because they think it's the right thing for you. I always want to make it clear that I don't want them to be thought of as monsters or bad people. I mean that the culture they know and understand is... it's passed from generation to generation, it's what they see as normal, it's what they themselves experienced in their families...” (V 4)
}

This kind of understanding for their family's behaviour is at least noted by some of the interviewees who have been able to rebuild their relationship with their parents, after an initial period of separation. All five interviewees found the need to separate from their families of origin when they decided to go against their wishes. This was either because they had not 
submitted to the marriage that had been arranged for them and had left their parents' home, or because, having initially given in and agreed to obey their parents, living with their spouse had subsequently become intolerable, and they decided to put an end to it and leave them. Some of the interviewees described that moment of separation as a kind of sudden 'click' or change of mindset.

The initial separation from their respective families, according to the women's testimonies, empowered them and allowed them to regain control of their lives. Two of them - precisely those with a stable emotional life, who later began to raise a family with a chosen partner have been able to rebuild their relationship with their parents and siblings. Another interviewee also seems to be in the process of rebuilding such a relationship. The cases of these three women suggest that this process of sudden separation with their daughters forced the families to reflect and reconsider their outlook on the situation. In some cases, this even seems to be a kind of regret.

"They tend to call me a lot, ask me a lot of questions... [My father] needs to do it to feel at ease. I think it is his way of asking for forgiveness. Of course, I'm very distant as well, and since they were responsible for something that caused me so much grief, I need my space, you know? It's fine if they reach out to me, but not if they smother me." (V 5)

The point here is not only that the experience left traces of negative sentiment among the families, but that it also led them to rethink and eventually change their attitudes. This is also shown in the fact that they did not set their younger daughters up for the same situation that the older ones had endured.

“They've failed because it's also a part of the culture, the culture they themselves have lived through. And they tried to make their children follow that culture, that tradition, call it what you want. It's hard, because it's thanks to what I went through that my sisters didn't have to go through it. (...) Yes, my sister is 23 years old and she's chosen her own partner and that's fine. My parents have got tired of fighting it all." (V 2)

"I have sisters, but they haven't been through the same thing. I was the first one it happened to and because of that they didn't do it to my sister (...) They've never even suggested it to her. Also, my sister is a bit of a character too... and my parents must have thought that they'd already been through so much trouble, let's let her do her own thing. In fact, she lives in England; she went about four years ago and has been single there the whole time, and they haven't caused any trouble about her not being married." (V 4)

In some cases, the victims were able to rebuild emotional ties with their parents that were as strong as they had been before the marriage, holding them in the same high esteem. One of the interviewees even stated the following:

“I love my parents very much. They are the best in the world. Yes, they were wrong, but I wouldn't change them for anything in the world." (V 2)

\subsection{Assistance received by victims and intended models for support}

The victims we were able to interview were women who had received assistance from NGOs that provide support for victims, and who had maintained contact with these organisations. One had not received any such support at the time she left her parents' home, but the other four interviewees had been assisted at one point or another by these entities. However, this position did not hinder their ability to describe the support they had relied on beyond these organisations. They were also able to describe their views on how best to assist women who endure forced marriage, based on their own experiences.

Four of the interviewees considered the assistance they had received from the abovementioned specialist organisations to be a determining factor in resolving the conflict. Apart from this support, the assistance they had received tended to be fairly unprofessional, as some previous studies have already demonstrated (Chantler and McCarry, 2019; Love et al., 2018). 
One of the interviewees told us how, at the point when she left her parents' home, she believed that the conflict between them was more a question of ideology or worldview than anything else. Rather than emotional or psychological support, she therefore sought economic support to allow to her to live independently. In other cases described by interviewees, informal support was provided by neighbours, friends or even employers who found out that the women were going through a complicated situation and tried to help them. In all five cases, the interviewees refer to such informal support with affection, suggesting that it was sometimes unskilled, but always well intentioned. They express sympathy for the fact that it was not always effective, as the providers were unable to understand the complexities of the family situation. In contrast, two of the interviewees expressed strong criticisms about social workers who had attended to them at some point in the process. They believed that far from having any understanding of the problem, these professionals had even made the situation worse by intervening.

"I went to the social services at XXX, I explained to them that I had run away from home and they told me that I had to explain everything. They contacted the social worker at XXX [the family's location], who told them to go and see my siblings - basically, it obviously got a whole lot worse... and I said that above all I didn't want it to get out... but they made it public, and that was painful." (V 1)

"I looked for some kind of mediator around here in the social services and I don't know how the whole thing got turned around and they took [my father's] side... 'Well, he doesn't want to hurt you, why don't you make the journey and if you can't go through with it, then come back.' And I thought, 'Come on, do you know what you're saying? Do you know what it will mean if I go away with my ID card expired and then come back? Will you help me when I can't get back?' It's obviously very easy to say all that, but when you're in the situation..." (V 5)

All the interviewees had their own views on the most suitable kind of assistance, while the precision with which they described these hypothetical models varied according to the interviewee in question. Their ideas about what this support should include were necessarily influenced by the severity of the experience they had endured. All the interviewees agreed that victims required someone they could talk to about the experience of separation, who could support them in the empowerment process, listen to them and offer them psychological and emotional support. All interviewees considered some distance from their families of origin to be necessary, at least on a temporary basis, until the most difficult part of the crisis had passed. The accounts of those who had endured more violent behaviour from members of their own family, however, were more insistent on this point.

"I think it's very important to distance yourself from your family, because if not... I kept going back because I was getting closer to my family. You have to keep some distance, complete distance, until you feel strong enough (...). Lots of distance, mainly, and privacy, complete privacy." (V 1)

Along with this need for distance, which some interviewees stressed more than others, as mentioned, they also pointed to the importance of support being continuous - a lasting process through which the victim could become empowered in time. The victim's separation from their family and process of reaching independence was considered a long, gradual process.

\footnotetext{
"It's a lengthy process. If someone comes to you about this kind of thing you can't kick them out, you can't settle the case and think that in a year it'll all be over, because that's not how it works. It needs years of work, follow-up and support, obviously more at the beginning and increasingly less if the person starts to feel empowered." (V 4)
}

The kind of support provided during this long process should be diverse: it should unquestionably include emotional or psychological support, but also a place of shelter, the offer of a home in cases of emergency, and economic support, in order to help victims find work that would give them the independence of having their own income. One of the interviewees suggested that a "support network" was therefore required in order to offer all these services. 
In addition to the criteria mentioned above, the support provider should consist of individuals who are able to understand the situation that the woman in question is going through, and who are aware of the codes of conduct at work in the community she belongs to.

"You have to have a kind of mentor, for example, someone who has been through the same thing and can make everything a bit clearer for you, someone who'll understand... So people who provide support for women who are going through it need to understand a bit about the family context, because you can't help someone going through it if you don't understand what's going on for them at home, in their family (...) The woman needs to see that the person trying to help her understands the situation, that she at least has a bit of knowledge about how it works in the culture, how things are done in that community, because otherwise it feels a bit like, if you don't even understand what I'm going through, you can't help me." (V 4)

It is clear that individuals providing support to these kinds of victims must at least be professionally trained in the field, if they have not directly experienced and overcome similar circumstances themselves. Nonetheless, it should also be noted that some misgivings were expressed by the interviewees themselves about members of the same community as the victims intervening in support roles. One of the interviewees suggested, for example, that if this were ever the case, the individual should be a young woman. She explained the risk that an older woman might advise the victim to try to put up with the marriage, rather than putting an end to it. Another interviewee also warned about the double game that some community mediators play.

"There are mediators who are African, but who are 'mediators' in name only really, because they get on very well with the community and with the white community as well, because when they are with the African community they adapt so they aren't rejected, and when they are with the white community they adapt to them as well so they can keep their jobs. I think they play a double game and that's not acceptable: if you are a mediator and you really help the women, and you have to argue with their parents so their daughter doesn't leave, then you do it, you see?' (V 5)

Finally, without being specifically asked about the issue, one of the interviewees - who provided a very coherent and detailed strategy for addressing forced marriage - made it clear that addressing the problem within the education system was crucially important for prevention.

\footnotetext{
"Also, I think a lot of work has to be done in education, especially at school, because I think you have to start preparing these girls from the age of 12, so the teachers are vigilant about it as well, so that they are aware that it's going on - because sometimes they don't know and the girls go on holiday to their countries of origin - so that they are kind of in a state of alert (...), so that they can give the warning signal to an organisation working on the issue." (V 4)
}

\subsection{Adequacy of using the criminal justice system}

Drawing to a conclusion, the positions of the interviewees were far from unanimous with respect to the role that the criminal justice system should play in resolving such cases. No general trend can be identified, as the different views were numerous and, again, varied according to personal experience.

One interviewee was clearly hopeful for the possibility of conflict resolution, as might be expected from the criminal justice system, and therefore openly in favour of the use of criminal law and retributive justice. She revealed that she had endured family violence constantly from a very early age. However, in her case, the potential she attributed to the criminal justice system had to do with its effectiveness in putting a stop to the kind of family abuse she had experienced, rather than putting an end to the forced marriage she had experienced afterwards.

The interviewees who had been subjected to family violence from their spouse, once married, also appeared hopeful that the criminal justice system might be able to put an end to 
this kind of abuse - especially so if the victim in question was looking for a way out of the forced marriage.

"Yes, definitely [the police can help], because a lot of women are scared to take this step. I always see those kinds of adverts on TV where you have to call a domestic abuse helpline, but to take that step is very difficult, even though you know you have to do it and you just need to dial three buttons and talk to someone. But it's very difficult. I took almost 10 years to report it. I knew I had to do it, but I was scared, and being scared can do you a lot of harm..." (V 2)

"I think that the role of the police, if the girl is underage, is to be more worried about her. But if the girl is over 21, she's the one who has to decide, even if she was forced into it, if she wants to stay married or not. If the man doesn't want her to leave and abuses her, then that could be reported of course. But if she's legally an adult and she doesn't want to leave, what can the police do?" (V 3)

Finally, those who had neither endured violence from their family of origin nor been forced into marriage with a man who abused them physically or emotionally were much more wary when it came to listing the virtues of the use of the criminal justice system, as a solution to the issue of forced marriage. As shown in the extract below, these interviewees suggest that the use of criminal justice is appropriate when violence has been used to force the daughter into marriage, but when pressure or ideological or cultural differences between parents and children are at the root of the conflict, the use of criminal justice serves little purpose in rebuilding family relationships.

"I didn't want the social services to get behind them because I didn't want criminal justice proceedings either. It's not a solution to the problem, because what happens with my father in prison? I mean, what good is that going to do for me and him? In fact, he never abused me physically, it's more a kind of clash of ideologies, that's all (...) If I had ended up getting married that would be different, if they had forced me into marriage, if I had been 'recruited' as they say, then that would be different, because there are cases where they have girls trapped in these situations. But in my case, he was far away and I'm here. The only issue was the conflict between me and my parents, but there's always different degrees of that." (V 4)

In this sense, the views of the interviewees reflect those from previous academic studies that warn against the use of criminal justice alone to combat the issue of forced marriage. This can place the victim in the double bind of being forced to report their own family of origin in order to obtain legal protection, and also having to submit to the dictates of Orientalism or racial discrimination (Askola, 2018; Ebeturk and Cowart, 2017; Gill and Anitha, 2011b; Igareda, 2017; Love et al., 2018; Patton, 2018; Sabbe et al., 2014; Sapoznik Evans, 2017; Torres, 2015; Villacampa, 2018).

As a final point - with a note of caution that family conflicts still persist in some cases where direct violence was not used - when the interviewees were asked about the possibility of mediation instead of retributive criminal justice as a way out of such situations, they were sceptical about this providing a potential solution. Their misgivings were related to the danger they perceived that mediation could possibly be used as a way to pressure women into staying in the marriage. Only one interviewee considered that this could be an effective long-term solution, insisting, however, that it would be ill advised to resort to this at the time of the conflict. It would only be useful at a later point, when the victim had gained some distance from their family of origin and the parents had had time to reflect, to see what was really happening, and even to change their minds. The interviewee also insisted that at this later point the mediator still needed to understand both points of view.

\section{Discussion and conclusion}

The objectives of the qualitative study came down to two main areas of focus: on the one hand, reaching a deeper of understanding the effects of forced marriage on victims; and on the 
other, identifying their needs for protection. Regarding the first point, the study has led us to conclude that although the strongest means of coercion are hardly ever used (or are at least rarely seen in the initial stages of forced marriage), victims are expected to be passive participants in the circumstances in which they are married or engaged by their families, they are not allowed nor expected to make decisions for themselves, lacking agency on the matter despite their attempts to challenge the situation. In cases in which the marriage does take place, the methods used to force the victim into submission become increasingly stronger and more violent as the process unfolds. This is such that we can clearly state that the three cases where marriages took place become cases of forced marriage, even from the perspective of the narrow and traditional concept of forced marriage. These aspects must be taken into account, therefore, if we are to characterise forced marriage accurately, that is, as a process more than as an event (Chantler and McCarry, 2019), including cases where mechanisms such as violence or intimidation are used, not only to enter into, but also to remain in an unwanted marriage (Gangoli et al., 2011), as well as those in which coercive control is the mean used to force (Anitha and Gill, 2009, 2011a) or situations of risk in which the marriage has not yet taken place (Chantler and McCarry, 2019) .

Victims' accounts also pointed to the fact the suffering of such abuse brought about the breakdown of the marriage, a liberation for the women, albeit also intrinsically linked to the much more emotionally painful process of separating from their families of origin. Their initial response to the announcement that they had to marry was often characterised by defiance, or occasionally resignation. Throughout the process of forced marriage, the victims also experienced feelings of fury, defencelessness and frustration as they realised their families would not yield. Furthermore, they experienced the huge emotional toll of having to live between two worlds: their own, and the one in which their family were settled.

Regarding the victims' specific needs for protection, the kind of assistance the interviewees considered most suitable varied according to the severity of their experiences. However, they all agreed on the necessity of an empowerment process where victims could be listened to and understood, and on the need for distance from their family of origin, at least on a temporary basis. During the empowerment process, which should be extended for a period of time, the victim must receive comprehensive assistance - emotional and psychological support, emergency shelter and longer-term accommodation, and professional training - from individuals with an understanding of the complexities of the family conflict. Finally, the interviewees did not consider the use of the criminal justice system to be the best solution, except in cases where extreme violence was used by the family of origin or the spouse. Neither did they welcome the use of restorative justice mechanisms before the victim is able to gain the distance needed from her family of origin and begin the empowerment process.

In spite of the limitations of this study, due to the reduced size of the sample, the testimonies of the victims themselves lead us to conclude that an effective approach to forced marriage must treat the practice as a form of gender-based violence, rather than as a question that is only related to the cultural communities in which the women are integrated - although, the relevance of their origins in explaining this type of victimisation must be acknowledged. The official response to forced marriage must not, therefore, be limited to criminalisation of the practice, as Orientalist views have advocated (Ebeturk and Cowart, 2017; Sabbe et al, 2014). Instead, a victim-centric approach made up of preventative measures and, above all, victim protection as well as prosecution, is crucial (Villacampa, 2018). From this perspective, given that the women may suffer many different kinds of discrimination when subjected to these experiences, an intersectional approach addressing the variety of factors of subordination that converge in this form of gender-based violence must be the starting point to deal with it (Arnold and Ake, 2013; Crenshaw, 1989, 1991; Nash, 2005; Nixon and Humphreys, 2010; Sokoloff and Dupont, 2005). Measures of prevention and protection adopted must consider all 
kinds of discrimination experienced by victims, not only those linked with gender, but also those referred to their cultural background and social or economic position. With a view to prevention, informative programmes should be devised and implemented through the education system for girls and young people, especially among groups at risk, that should be determined not on the basis of cultural prejudices against certain minorities, but on scientific outcomes from victimisation surveys, when possible, leading to implement strategies of secondary prevention of victimisation. In order to do so, multi-agency working would be crucial, with teams composed by social work, education system and victim assistance professionals who could design awareness raising and education programmes as well as establish a mechanism for the referral of women in situations of risk to be forced to marry between the education system and victim assistance services.

Measures of protection should go beyond the criminal justice system, since it has been shown how the mere criminal approach to this reality has not only dubious efficiency in preventing these cases from happening, but also in improving the welfare of those who have suffered these situations, forcing the victims to report their closest relatives to obtain any kind of protection. Fundamentally, civil measures, similar to those included in the British Forced Marriage (Civil Protection) Act 2007, must be adopted which, while helping to prevent or put an end to unwanted marriages, might also allow the victim to reconnect with her family of origin when she is empowered enough and the risk of revictimisation is vanished. That is, at least in cases where forced marriages are produced in contexts of coercive control, but where violent behaviours have not evidently surfaced, the legal system should provide for noncriminal protective measures and assistance policies enabling to rebuilt family ties through the reeducation of families in respecting their daughter's opinions and decisions once victims have overcome this situation. This requires victim assistance services to be staffed by professionals equipped with cultural training and an understanding of the complex mix of factors at work in such practices, in order to prevent the victims' betrayal from certain not trained administrative services that previous research has shown (Chantler and McCarry, 2019). Also a protective level a multi-agency working scheme would be appropriate, since again not only victim assistance, but also educational system and forensic professionals are needed to assess the adequacy of the adoption of certain protective measures and to check their execution. This conformation of the teams in charge of victims' protection in cases of forced marriages would enable them to avoid the danger either of overreacting -by separating the victim from her family when it can be counterproductive- or, on the contrary, of being too passive -by refraining to intervene in situations of subtler family abuse leading to forced marriage- in which less trained or not multidisciplinary professional agencies may incur.

Finally, even in cases where the use of violence renders criminal justice unavoidable, we must endeavour to find a model that does not force victims to choose between protection and contact with their family of origin, at least in those cases in which maintaining family bonds can benefit the victim somehow. This holistic and intersectional approach towards forced marriage comes within the framework of a criminal justice system which is culturally sensitive, able to communicate with victims and their families and offer them support, without avoiding the implementation of restorative, instead of retributive, justice mechanisms to deal with these cases when it is considered beneficial on grounds of technical assessment.

The legal victim-centric treatment of forced marriage proposed here is far from the legal approach to gender-based violence adopted in Spain since the approval of the 2004 Act on Comprehensive Protection against Gender Violence. The legal policy on gender-based violence in this country is focused primarily on the recourse to the criminal law, becoming very punitive and having little concern for the needs expressed by victims, on the assumption that they expect offender prosecution rather than protection from the system. As a result, the protection system adopted to combat any form of gender based violence is conformed merely 
by the incrimination of certain behaviours and the implementation of criminal procedural protection measures. Furthermore, the legal approach to gender-based violence so far looks like it will remain, since the State Agreement on Gender Based Violence signed by the Spanish Government in December 2017 insists on the adoption of this perspective and announces the approval of punitive legislative reforms encompassing also more contemporarily identified cases of gender violence, such as forced marriage, without any major change in the legal and institutional approach to them. This is why the adoption of the aforementioned victim-centred approach to forced marriages in Spain would require not only a shift in the legislator's sensitivity to forced marriage itself, but rather towards the phenomenon of gender-based violence as a whole.

\section{References}

Anitha S and Gill AK (2009) Coercion, Consent and the Forced Marriage Debate in the UK. Feminist Legal Studies 17: 165-184.

Anitha S and Gill AK (2011a) Reconceptualising consent and coercion within an intersectional understanding of forced marriage. In Gill AK and Anitha S (eds) Forced Marriage. Introducing a social justice and human rights perspective, London and New York: Zed Books, pp. 46-66.

Anitha S and Gill AK (2011b) The social construction of forced marriage and its 'Vitim' in media coverage and crime policy discourses. In Gill AK and Anitha S (eds) Forced Marriage. Introducing a social justice and human rights perspective, London and New York: Zed Books, pp. 112-134.

Arnold, G and Ake, J. Reframing the Narrative of the Battered Women's Movement. Violence Against Women, 2013, 19(5): 557-578.

Askola H (2018) Responding to Vulnerability? Forced Marriage and the Law. UNSW Law Journal 41 (3): 977 1002.

Begikhani N, Gill AK and Hague G (2015) Honour-Based Violence. Experiences and Counter-Strategies in Iraqi Kurdistan and the UK Kurdish Diaspora, Farnham-Surrey: Ashgate.

Braun V and Clarke V (2006) Using Thematic analysis in Psychology. Qualitative Research in Psychology 3 (2): 77-101.

Bunting A, Lawrance BN and Roberts RI (2016) Something Old, Something New?. Conceptualising Forced Marriage in Africa. In Bunting A, Lawrance BN and Roberts RI (eds) Marriage by Force? Contestation Over Consent and Coercion in Africa. Athens (Ohio): Ohio Universtiy Press, pp. 1-42.

Chantler K, Gangoli G and Hester M (2009) Forced marriage in the UK: Religious, cultural, economic or state violence?. Critical Social Policy 29 (4): 587-612.

Chantler K, McCarry M (2019) Forced Marriage, Coercive Control, and Conducive Contexts: The Experiences of Women in Scotland. Violence Against Women, First Published March 1, 2019: 1-21.

Corbin J and Strauss A (2008) Basics of Qualitative Research, $3^{\text {rd }}$ edition. Los Angeles, London, New Delhi, Singapore: Sage Publications.

Crenshaw K (1989) Demarginalizing the Intersection of Race and Sex: A Black Feminist Critique of Antidiscrimination Doctrine, Feminist Theory and Antiracist Politics. The University of Chicago Legal Forum Iss 1(8): 139-167.

Crenshaw K (1991) Mapping the Margins: Intersectionality, Identity Politics, and Violence Against Women of Color. Standford Law Review 43 (6): 1241-1299.

Denzin NK and Lincoln YS (2002) Introduction. The Discipline and Practice of Qualitative Research. In Denzin NK and Lincoln YS (eds) The Sage Handbook of Qualitative Research, 3rd. edition. Thousand Oaks, London, New Delhi: Sage Publications, 2002, 1-32. 
Ebeturk IA and Cowart O (2017) Criminalization of forced marriage in Europe: A qualitative comparative analysis. International Journal of Comparative Sociology 58 (3): 169-191.

FRA (European Agency for Fundamental Rights) (2014) Addressing forced marriage in the EU: Legal provisions and promising practices. Available at: https://fra.europa.eu/en/publication/2014/addressing-forced-marriage-eulegal-provisions-and-promising-practices (accessed 22 February 2019).

Gangoli G and Chantler K (2009) Protecting Victims of Forced Marriage: Is Age a Protective Factor?. Feminist Legal Studies 17: 267-288.

Gangoli G, Chantler K, Hester M and Singleton A (2011) Understanding forced marriage: definitions and realities. In Gill AK and Anitha S (eds) Forced Marriage. Introducing a social justice and human rights perspective, London and New York: Zed Books, pp. 25-45.

Gill A (2014) Introduction: 'Honour' and 'Honour'-Based Violence: Challenging Common Assumptions. In Gill AK, Strange C and Roberts K (eds) 'Honour' Killing and Violence. Theory, Policy and Practice. New York: Palgrave Macmillan, pp. 1-23.

Gill AK and Anitha S (2011a) Introduction: framing forced marriage as a form of violence against women. In Gill AK and Anitha S (eds) Forced Marriage. Introducing a social justice and human rights perspective, London and New York: Zed Books, pp. 1-24.

Gill AK and Anitha S (2011b) Forced marriage legislation in the UK: a critique. In Gill AK and Anitha S (eds) Forced Marriage. Introducing a social justice and human rights perspective, London and New York: Zed Books, pp. 137-157.

Gill AK and Brah A (2014) Interrogating cultural narratives about 'honour' based violence. European Journal of Women's Studies vol. 2 (I): 72-86.

Gill AK and Harvey H (2017) Examining the impact of gender on young people's views of forced marriage in Britain. Feminist Criminology 12 (1): 72-100.

Guest G, McQueen KM and Namey EE (2012) Applied Thematic Analysis. Los Angeles, London, New Delhi, Singapore, Washington DC: Sage Publications.

Hamel C (2011) Immigrées et filles d'immigrés: le recul des mariages forcés. Population et Sociétés 479: 1-4.

Hemmings J and Khalifa S (2013) I Carry the Name of my Parents': Young People's Reflections on FGM and Forced Marriage: Results from peer studies in London, Amsterdam and Lisbon. Available at: https://forwarduk.org.uk/wp-content/uploads/2016/06/I_carry the name_of my Parentsyoung_peoples_reflections_on_FGM_and_forced_marriage.pdf (accessed 22 February 2019).

Hester M, Chantler K, Gangoli G, Devgon J, Sharma S and Singleton A (2008) Forced Marriage: the Risk Factors and the Effects of Raising the Minimum Age for a Sponsor, and of Leave to Enter the UK as a Spouse or Fiancé(e). Bristol: University of Bristol. Available at: http://www.bristol.ac.uk/medialibrary/sites/sps/migrated/documents/rk6612finalreport.pdf (accessed 22 February 2019).

Home Office (2000) A Choyce by right. The report of the working group on forced marriage. Available at: https://www.basw.co.uk/system/files/resources/basw_22604-2_0.pdf (accessed 22 February 2019).

HM Government (2010) The right to Choose: Multi-agency statutory guidance for dealing with forced marriage, second (revisited) edition. Available at https://www.gov.uk/government/publications/the-right-to-choose-multiagency-statutory-guidance (accessed 22 February 2019).

Home Office-Foreign \& Commonwealth Office (2018) Forced Marriage Unit Statistics 2017. Available at: https:/www.gov.uk/government/statistics/forced-marriage-unit-statistics-2017 (accessed 22 February 2019).

Igareda N (2017) Forced marriage in Europe: from a migration problem in a global world to the old fenomenon on gender violence. Rivista di Criminologia, Vittimologia e Sicurezza XI (2): 4-12.

Igareda N, Barcons M, Lotti MR and Leye E (2016) Matrifor. Approaching forced marriages as a new form of trafficking in human beings in Europe. Report. Brussels: European Commission.

Kazimirski A, Keogh P, Kumari V, Smith R, Gowland S, Purdon S and Khanum N (2009). Forced MarriagePrevalence and Service Response. National Centre for Social Research, Research Report No DCSF-RR128.

Love H, Dank M, Esthappan S and Zweig J (2018) Navigating and Unclear Terrain: Challenges in Recognizing, Naming, and Accessing Services for "Forced Marriage". Violence Against Women, 1-22. 
Maqueda M (2016) El hábito de legislar sin ton ni son. Una lectura feminista de la reforma penal de 2015. Cuadernos de Política Criminal 118: 5-42.

Marshall C and Rossman GB (2006) Designing qualitative research. Thousand Oaks, London, New Delhi: Sage Publications.

Martin LV (2018) Restraining Forced Marriages. Nevada Law Journal 18: 919-1003.

May KA (2005) Conocimiento abstracto: un caso a favor de la magia en el método. In Morse JM (ed) Asuntos críticos en los métodos de investigación cualitativa. Alicante: Publicaciones Universidad de Alicante, pp. $37-52$.

Mirbach T, Schaak T and Triehl K (2011) Zwangsheiratungen in Deutschland -Anzahl und Analyse von Beratungsfällen. Wissentschaftliche Untersuchung im Auftrag des Bundesministeriums für Familie, Senioren, Frauen und Jugend. Available at: https://www.bmfsfj.de/bmfsfj/service/publikationen/zwangsverheiratung-indeutschland---anzahl-und-analyse-von-beratungsfaellen/80740 (accessed 22 February 2019).

Naber N (2010) Decolonizing culture. Beyond Orientalist and Anti-Orientalist Feminisms. Abdulhadi R, Alsultany E and Naber N (eds) Arab \& Arab American Feminisms. Gender, Violence \& Belonging, Syracuse, New York: Syracuse University Press, pp. 78-90.

Nash JC (2005) From Lavender to Purple: Privacy, Black Women, and Feminist Legal Theory. Cardozo Women's Law Journal 11: 303-319.

Nixon J and Humphreys C (2010) Marshalling the Evidence: Using Intersectionality in the Domestic Violence Frame. Social Politics 17 (2): 137-158.

Patton, C. (2018). Racialising domestic violence: Islamophobia and the Australian forced marriage debate. Race \& Class 60 (2): 21-39.

Psalia E, Leigh V, Verbari M, Fiorentini S, Dalla Pozza V y Gomez A (2016) Forced Marriage from a gender perspective, Study for the Femm Committee. Directorate General for Internal Policies. Brussels: European Parliament.

Razack SM (2004) Imperilled Muslim Women, Dangerous Muslim Men and Civilised Europeans: Legal and Social Responses to Forced Marriages. Feminist Legal Studies 12: 197-174.

Sabbe A, Temmerman M, Brems E and Leye E (2014) Forced marriage: an analysis of legislation and political measures in Europe. Crime, Law and Social Change 62(2): 171-189.

Said EW (1979) Orientalism. New York: Vintage.

Sapoznik Evans KA (2017) Forced Marriage in Canada: To Criminalize or Not to Criminalize?. Canadian Journal of Human Rights 6: 49-85.

Sokoloff NJ and Dupont I (2005) Domestic Violence at the Intersections of Race, Class, and Gender. Violence Against Women 11(1): 38-64.

Swegman C (2016) The Intersectionality of Forced Marriage with Other Forms of Abuse in the United States. National Resource Center on Violence Against Women. Available at: https://vawnet.org/material/intersectionality-forced-marriage-other-forms-abuse-united-states (accessed 10 September 2019).

Tahirih Justice Center (2011) Forced marriage in immigrant communities in the United States. National Survey Results. Available at: http://www.tahirih.org/pubs/forced-marriage-in-immigrant-communities-in-the-unitedstates/ (accessed 22 February 2019).

Torres N (2015) Matrimonio forzado: aproximación fenomenológica y análisis de los procesos de incriminación. Estudios Penales y Criminológicos XXXV: 831-917.

Trama di Terre (2014) Matrimoni forzati, combinati e precoci. Vademecum per operatori e operatrici. Available at:

http://informa.comune.bologna.it/iperbole/media/files/violenza_contro_donne_vademecum_matrimoni_forzati 2014.pdf (accessed 22 February 2019).

UNICEF (United Nations Children's Fund) (2001) Innocenti Digest no.7: Matrimonios prematuros. New York: UNICEF.

UNICEF (2008) Child marriage and the Law, Legislative Reform Initiative Paper Series. New York: Division of policy and planning, UNICEF. 
UNICEF (2014). Ending Child marriage. Progress and prospects. New York: UNICEF.

Villacampa C and Torres N (2019) El matrimonio forzado en España. Una aproximación empírica. Revista Española de Investigación Criminológica 17: 1-32.

Villacampa C (2018) Política criminal española en materia de violencia de género. Valoración crítica. Valencia: Tirant lo Blanch.

Wijffelman A (2017) Child marriage and family reunification: an analysis under the European Convention on Human Rights of the Dutch Forced Marriage Prevention Act. Netherlands Quarterly of Human Rights 35 (2): 104-121.

Yurkadul G and Kortewg AC (2013) Gender equality and immigrant integration: Honor killing and forced marriage debates in the Netherlands, Germany, and Britain. Women's Studies International Forum 41: 204-214. 